\title{
A study of the barriers of implementation of accounting information system: Case of listed companies in Tehran Stock Exchange
}

\author{
Mahdi Salehi ${ }^{1}$ Abdoreza Abdipour ${ }^{2}$ \\ ${ }^{1}$ Accounting and Management Department, Islamic Azad University, Takestan Branch, Iran, \\ 2Payame Noor University, Andimeshk Branch, Iran \\ mahdi_salehi54@yahoo.com
}

\begin{abstract}
Accounting information system is one of subsystems in management information system that is very important in all companies. The current study reviews barriers in implementation by postulating six hypotheses of accounting information system (middle managers, human resources, organizational structure, environmental factors, financial issues, and organizational culture) in companies listed on Tehran Stock Exchange. Finally, some results were obtained in this manner: barrier of organizational structure with 26 percent, middle managers with 26 percent, human resources with 25 percent, environmental factors with 21 percent, organizational culture with 19 percent and finally financial issues with16 percent were identified as barriers factors influencing on the establishment of accounting information systems in listed companies on Tehran Stock Exchange. Generally to eliminate these barriers, management, financial managers and staff must be trained practically by experienced teachers in accounting information systems to use the specialist and professional managers, to lengthen position of managers, to clear financial issues, to inform benefits of system establishment to company's managers. By giving reward to managers and staff try to encourage these people to use the new system. To justify staff that the establishment of new system would be their advantages; by the lever of reward, to encourage staff to compete in learning and work with the system in staff and learn to compete with systems that can accelerate performing and implementing the system.
\end{abstract}

Key words: Accounting information systems, Corporate accounting system, financial system

\section{Introduction}

Today, dramatic changes have occurred in the field of Information Technology (IT) and its progress has been so pervasive so that it has created changing trends in different in areas. The most important features of it are; high speed data processing, extremely high accuracy, and high speed access to information, to be up-to-date, the possibility of electronic exchange of information, high quality, very cheap and declining price. By considering these factors there will be no need to justify the use of IT in today's world (Salehi et al., 2010a). Addition in accounting has to use and apply all or some of the new techniques in their services and obligations. So, providers of information especially accountants, should be the providers of advanced and high-quality information so that their services to be bought in high prices. Otherwise, in the future they will not have any place. Accounting information System (AIS) is developed between one or two or more units of a company to achieve a specific goal (Salehi et al., 2010 b; Salehi and Alipour, 2010). It contains small sub-systems that support larger systems, includes people, methods, information and software and information technology infrastructures (Romney and Barrett, 2003). System consists of a set of incorporated components that are affiliated to achieve one or several particular goals in a way that, if one or more input can enter in it, one or more output exits (Frederick, 1984). AIS is a completely designed system for the production, collection, organization (processing), storage, retrieval and dissemination in an institution, organization or any other defined areas of society. AIS can helps business units and solve short-term problems of managers in the areas of final price, cost and cash flow through providing information to support and supervision of companies in the dynamic and competitive environment, and to help the integration of these companies and the operational considerations and strategic programs in long term (Mitchell et al., 2000). Progress in the fields of accounting, information technology and information systems during the past two decades suggest conditions to consider the role of accounting information system. For example, the evolution of active database technology, implementing new models, such as accounting resources and factors of planning resources and allowing accounting information to attract financial old data. 
Available literatures show little evidence of developing AIS within medium companies. In fact considerable evidences suggest that financial accountings in medium companies are the main source of information and management (McMahon and Davies, 1994).

\section{Advantages of JIT}

The advantages of the JIT philosophy are many. Giunipero et al., (2005) say that JIT has led to several benefits which include lower production cost, higher and faster throughputs, better product quality, reduced inventory costs, and shorter lead times in purchasing. According to an American study of U.S. Manufactures, companies can expect improved performance in lead times, quality levels, labor productivity, employee relations, inventory levels and manufacturing costs (White, Pearson, and Wilson, 1999).

Fullerton and McWatters (2001) summarised benefits in to five categories: quality benefits, time-based benefits, employee flexibility, accounting simplification and firm profitability. The increase in performance is usually attributable to a decrease in inventory levels, smoother production flow, lower storage cost and ultimately a decrease in average cost per unit (Hall, 1989). Callen et al., (2000) reported that JIT plants have significantly less WIP than non-JIT plants. JIT plants also store fewer finished products and have lower variable and total costs than the non-JIT equivalent. Callen et al., (2000) further found that JIT plants are significantly more profitable than non-JIT plants, but are neither successful at minimizing WIP and costs nor maximizing profits. It is possible to observe that traditional performance measurement system is inconsistent with JIT system benefiting from technological innovations at a maximum level and also that it prevents or hides broad-based effectiveness of new production methods. In this sense, the restrictions of traditional measurement system in JIT environment might be listed as follows:

1. Continuous development in production process is basic element in JIT manufacturing environment. To reach this aim easily, it's intended to make flow of production possible with minimal parties and decreasing stock levels to a minimum. Yet, production and productivity measures of traditional understanding have reported that the productivity is low when small-lot production is made (Drury, 1990). For this reason, traditional accounting system suggests increasing batch capacity rather than decreasing lot size, which leads to raising stock levels, long supply process, increasing cost and declining customer satisfaction (Mcnair et al., 1990).

2. As in standard costing, appropriate operational control of traditional accounting system cannot be carried out in today's production environment (Allott, 2000; Cheatham and Cheatham: 1996; Ezzamel, 1992). Besides, due to the reliability and consistency of manufacturing processes in JIT environment, deviations do not exist or exist in quite low level and it also leads to less use of deviation analyses.

3. JIT manufacturing system changes will bring about changes in information requirements (Upton, 1998). As it is known, normally traditional performance, reporting is prepared monthly or weekly and cannot detect on time real reasons of processes that are not realized as expected. Yet, in JIT production system there is a possibility of short production cycle, so it requires information for the problems coming out in accordance with one-day or "real time" principal.

Ahmad et al., (2004) presented potential benefits and performance improvements achieved through JIT implementation. The summary of main benefits of JIT is listed below:

1. Reduced process time, setup time and lead time;

2. Reduced raw material, wip and finished goods inventory levels and lot size;

3. Improved machinery and reduced machine breakdowns and downtimes;

4. Minimized space requirement;

5. Improved flow of products;

6. Lowered production costs;

7. Simplified production processes;

8. Improved quality;

9. Improved flexibility, multifunctional ability, motivation and problem solving capability of employees;

10. Increased productivity and performance; 
11. Improved consistency of production scheduling; and

12. Increased emphasis on supplier integration

Following are the main objectives of the study:

1. Identify barriers in the establishment of AISs in companies.

2. Provide strategies for the establishment of the obstacles companies AIS in listed companies on TSE.

\section{Theoretical issues and review of literature}

IT is a company's key infrastructure that includes physical information technology infrastructures, information technology of human resources to get information (technical and managerial skills), and technology of irreplaceable resources (Bharadvj, 2000). An important study problem in management accounting and concern about AIS decision-making with organization regarding the need for information is communication and control of accounting information system. Computer system is based on a process that supports financial data for decision-making tasks of managers within the frame of coordination and control of company's activities that in the researches of different studied models, between accounting information system with technology organization, organization's structure and organizational environment have been studied (Chen and Hall, 1994).

AIS is an important mechanism of an organization that is vital for effective management decision-making in controlling organization (Zymrmn, 1995). Generally, AIS is classified in two categories: a: effective decision-making for information that is largely for control of organization and $b$ : to facilitate information that is mainly used for coordination of organization in decision-making are used (Kern, 1992). Effectiveness of AIS to increase system integration is to improve internal communications throughout the organization (Huber, 1990). Top management team with various planning and management information system influences on strategic performance (Gil, 2009). Behavioral changes following Joint development show AIS support and participation of users that has been influencing on in accounting information system development and improved financial performance, which eventually lead to successful troubleshooting cost accounting system, are based activities (Alden burg et al., 2009). About the productivity of information technology within the information systems in public accounting is that a small number of respondents aware of the technology components were the major component of respondents information technology data, but not the information system Accounting and usefulness were aware of the development and effects in this study started the organization, human resources management and knowledge of technology and acceptance of data were evaluated (Madshary, 2008).

Comparative advantage as a model of efficiency value accounting information systems research for scholars is significantly effective and that represent the financial resources and human resources as the two basic pillars of research and development supplement industry regarding information systems that are accounting absolute superiority ensures business operations (Eles, et al., 2008). Management stress on critical factors in success to implement organizational resources planning systems suggests that the selecting appropriate time, completing the project by one management, training personnel, superiority of project results in comparison with other projects, use of consultants, management interaction with users, the use of project control committee, shows the difference between successful and unsuccessful projects (Bradley, 2008). Test of textual factors and the impact of characteristics of technology on implementing auditing decisions is in such a way that the use of computer techniques by experienced auditors shows that companies which have experienced the ability of influencing on implementation of new technology using long-term budgets, have assed different courses through indirect control of the software (Curtis and Payne, 2008).

Intelligent business systems and measuring, its effects in connection with business processes and organizational performance when measuring performance is important as information technology systems through specialized texts and literature is outstanding (Bashir, et al., 2008). Test of the influence of international investors on the quality of accounting information demonstrates that the choice right of investment and increasing work quality of international investors on the quality information has influenced on Russian accounting companies (Baguya, 2008). Current economic and the traditional model of accounting reports: challenges and opportunities ahead of AIS researches prove that the economy in real condition can accelerate measurement and evaluation of business. Decision-making processes as a 
new business model results in decrease of internal and hidden processes. Therefore, AISs together with research literature have been successful in development of new models to accelerate accounting processes (Vasarahly and Els, 2008). Organizational determining factors acceptance and implementation of information technology in mean companies: private and public companies shows that limiting factors in the implementation and information technology overhaul, reform arranged, changes, lack of qualified personnel and Run the same technology and information systems quality are essential (Muyanu and Brook, 2007).

Strategic Planning of information systems: case study in financial services companies in Germany represents that lack of scientific literature in implementation of strategic information systems planning, data transfer isn't mainly due to scientific literature, although scientific literature inspiring, in practice to run strategic planning, information system not included. Professional characters of management and different resources are of scientific characters. Thus the role of management in the information technology practice through the opinions of staff need more experience (Tabnar, 2007). More regulatory practices on information technology function of information technology organizations and business sector common understanding with the goals are associated with information technology. For example, active participation in the committee information technology, trade balance, decisions regarding technology information and understanding of strategic policies and administrative information technology in successful exploitation of information technology projects (Buyan et al., 2007). Appropriate review between designing of AIS and performance of commercial units by analyzing strategies explains that high performance of commercial units depends on a wide range of accounting information systems (Boolean, 2007).

Study of integrated information systems literatures of management accounting with consideration to the existing strengths within the framework of management accounting elements, new integrated information systems of accounting results in more development and understanding of theatrical frameworks in this regard. It identifies research gaps and suggests using research opportunities with different patterns and different methods. Ranking of AISs on performance of medium companies in Malaysia after study of 310 companies through electronic questionnaire showed that, a significant and important part of medium companies in Malaysia placed in high rank, and only a limited number of medium companies because of low organizational performance were in low level of accounting information systems (Nur Azizi and Kynk, 2005). Factors of users' concentration, measurement, and report making, quality of provided management information, reviewing and checking group work of outcomes affect the quality of accounting information (Hong-Jiang, 2005). To develop and spread of AIS a special team should be organized for designing input and output concepts and processing stored information so that company's decisions for main outputs and comparing of them with computer information to be possible and achievable (Romney and Stein, 2003).

Future development of AIS in investment shows that the successes in avoiding risking the capital of companies are of five categories as: 1- clear and bright offers. 2 - Internal changes in institution investment. 3 - The variety of variables and repeating information change 4 - More use of information for supportive decisions support 5- world-wide impacts on investment. These evidences are good reasons for the judge and further research in the future and development of AIS (Gavyn et al., 1997). Mistry (2005) found that, though JIT has been widely implemented, interest in documenting its impact on financial performance and productivity was generated during last few decades. For example, Inman and Mehra (1993) established the link between JIT benefits and bottom line financial measures. Olsen (2004, cited in Swamidass, 2007) is stated that "lean/JIT firms tend to have better return on equity", since lean/JIT is associated with low inventories. However, according to Fullerton and McWatters, (2002), the use of financial performance measures under the present competitive market conditions appears unsustainable due to various reasons. Therefore, performance measurement system of a corporate using JIT production system should support basic variations such as increasing product or service quality, continuous development and reducing the losses (Hendricks, 1994). 


\section{Chart (1): General Plan of Financial Automation}

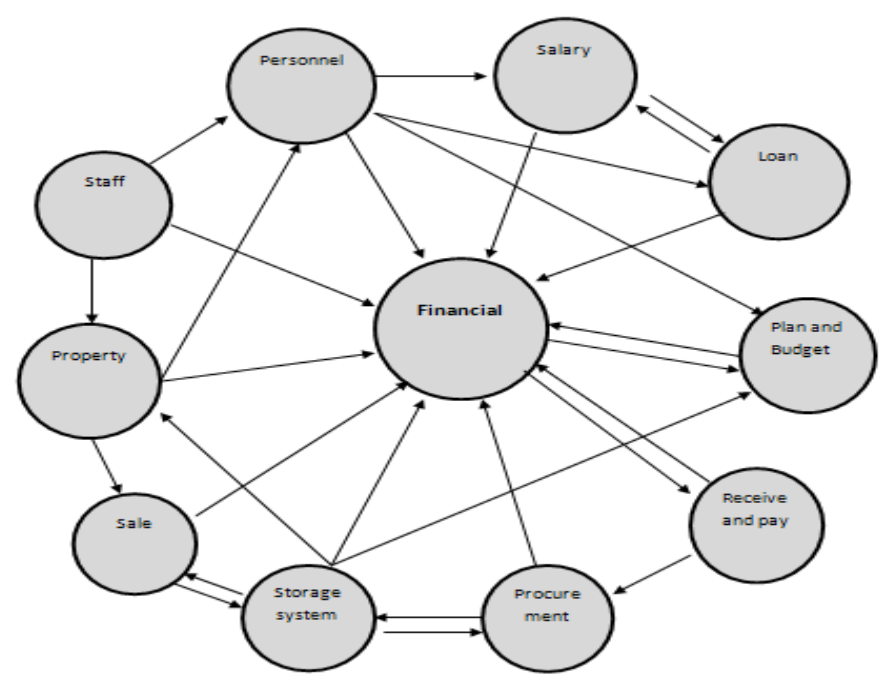

\section{Research methodology}

The statistical society of the study includes the financial managers of the companies listed on Tehran Stock exchange (TSE). For this purpose, a number of 442 companies were selected from TSE website. From the entire number of the selected companies 36 companies were omitted from the list of listed companies of TSE following the session of Security Subscription Board on June 10, 2008. Eventually, the study was concentrated on 406 companies from 36 different industrial sectors. The statistical community in this research could be all of companies all over the country, but with different directions and limitations of the personal facilities and we limited statistical community and selected 100 companies listed on TSE. Research data collection instrument is a questionnaire which has been standardized in the academic community and validity of it considering the opinions of specialized literatures and comments of expert managers in relevant areas were analyzed and its validity is acceptable. In order to determine the proper size of the specimen and calculate the Cronbach $\alpha$ coefficient a pre-testing process was conducted. The methodology of the process was as follows:

A number of 13 questionnaires of which narration style had been confirmed were distributed by the researcher among the financial managers of the admitted companies of TSE as an initial specimen. The original data showed that, on average, the affectivity of financial expenses in order to establishing an internet financial reporting was rated at 13.90 with the standard deviation of 4 within the range of 5-25. In the society average comparison test, with the constant number of 15 (the middle point of the above range), at least, a number of 86 persons at $5 \%$ error rate provided 80.26 percent level of ability. In order to testing of hypotheses, T-Test was employed in the study which it fits to the testing of hypotheses.

\section{Research hypotheses}

H1: middle managers prevent the establishment of AIS in financial units.

H2: organizational structure prevents the establishment of AIS in the company's financial units.

H3: organizational culture prevents the establishment of AIS in financial units.

$\mathrm{H} 4$ : financial problems prevent the establishment of AIS in the company's financial units.

H5: labor prevents the establishment of AIS in financial units.

H6: environmental factors influencing on AIS prevent the establishment of the company's financial units.

\section{Data analysis}

In this section, demographic information of participants based on research experience and education level is presented in Table 1. 
Table 1: General information of participants

\begin{tabular}{cccc}
\hline Item & Variable & Frequency & Percentage \\
\hline \multirow{2}{*}{ Educational background } & Diploma & 26 & 26.80 \\
Field of the Study & B.A & 59 & 60.80 \\
& Accounting & 59 & 12.40 \\
& Management & 38 & 60.80 \\
& Lee than 5 years & 62 & 63.20 \\
Experience & 6-10 years & 28 & 28.80 \\
& 11-15 years & 7 & 7.20 \\
& Manager & 11 & 11.30 \\
designation & deputy & 7 & 7.20 \\
& expert & 41 & 42.30 \\
& clerk & 38 & 39.20 \\
\hline
\end{tabular}

\section{Testing of hypotheses}

H1: middle managers prevent the establishment of information systems in the company's financial units. In order to testing of the first hypothesis, One sample T-test is employed which the detail has presented in Table 2.

Table 2: The results of testing first hypothesis

\begin{tabular}{llll}
\hline \multicolumn{3}{c}{ Test Value=20 } \\
\hline First hypothesis & degrees of freedom & $\mathrm{T}$ & Significant level \\
Middle managers & 96 & 16.735 & 0.001 \\
\hline $\mathrm{H} 0: \mathrm{M}=20)$ & & & \\
$(\mathrm{H} 1:=\mathrm{M}>20$ & &
\end{tabular}

Information contained in Table 2 shows the level of significant 0.001 , and since the significant level is less than 0.005 shows the acceptance of hypothesis, so $\mathrm{H} 0$ is rejected and $\mathrm{H} 1$ is approved.

$\mathrm{H} 2$ : organizational structure prevents the establishment of accounting information system in the company's financial units.

Table 3 shows the results of testing of hypothesis, according to the results of Table 3 the research hypothesis is accepted.

Table 3: the results of second hypothesis

\begin{tabular}{|c|c|c|c|}
\hline \multicolumn{4}{|c|}{ Test Value $=7$} \\
\hline The second hypothesis & Degree of freedom & $\mathrm{T}$ & $\begin{array}{l}\text { Significant } \\
\text { level }\end{array}$ \\
\hline Organizational structure & 96 & 15.550 & 0.001 \\
\hline
\end{tabular}

HO: $M=7)$

$(\mathrm{H} 1:=\mathrm{M}>7$

Table 3 shows 0.001 level of significant, and since the significant level less than 0.005 is accepted, hypothesis $\mathrm{H} 0$ is rejected and, $\mathrm{H} 2$ is approved. Therefore, organizational structure is one of the barriers of the establishment of AIS in companies listed on TSE. 
H3: organizational culture prevents the establishment of accounting information systems in financial units. For the above hypothesis single-sample T-test using SPSS software with confidence level of 0.095 used and the results are mentioned in Table (4)

\section{Table (4): the results of testing third hypothesis}

Test Value $=12$

\begin{tabular}{clll}
\hline The third hypothesis & degree of freedom & T & Significant level \\
Organizational culture & 96 & 68.246 & 0.001 \\
\hline $\begin{array}{c}\mathrm{HO}: \mathrm{M}=12) \\
(\mathrm{H} 1:=\mathrm{M}>12\end{array}$ & & & \\
\hline
\end{tabular}

Information contained in table (4) shows significant level of 0.001 , and since the significant level less than 0.005 is, hypothesis H0 rejected, so H3 is approved. Therefore, organizational culture prevents the establishment of AIS in companies based in financial units of companies.

H4: financial problems prevented the establishment of accounting information system in the company's financial units.

Table (5): the results of fourth hypothesis

\begin{tabular}{llll}
\hline \multicolumn{3}{c}{ Test Value=6 } \\
\hline Fourth hypothesis & degree of freedom & T & Significant level \\
Financial problems & 96 & 28.426 & 0.001 \\
\hline
\end{tabular}

$$
\begin{aligned}
& \text { HO: } M=6) \\
& (H 1:=M>6
\end{aligned}
$$

Information contained in the table (5) show 0.001 level of significant, and since the significance level less than 0.005 , H0 rejected, therefore, financial problems prevent the establishment of AIS in companies listed on TSE.

H5: Labors don't prevent the establishment of AIS in financial units. For the above hypothesis one- sample T-test, using SPSS software with confidence level of 0.95 is used and the results are mentioned in Table (6).

Table (6): the results of testing fifth hypothesis

\begin{tabular}{lccc}
\hline \multicolumn{3}{c}{ Test Value $=17$} \\
\hline $\begin{array}{c}\text { fifth } \\
\text { hypothesis } \\
\text { Labors }\end{array}$ & degree of freedom & $\mathrm{T}$ & Significant level \\
& 96 & 887.67 & 0.001 \\
$\mathrm{HO}: \mathrm{M}=17)$ \\
$(\mathrm{H} 1:=\mathrm{M}>17$
\end{tabular}

Information contained in the table (6) shows 0.001 level of significant, and since the significance level less than $0.005, \mathrm{H} 0$ rejected, so $\mathrm{H} 5$ is approved. Hence we can say that issues related to human resources are of barriers in the establishment of accounting information system in companies located in stock exchange.

H6: environmental factors affecting accounting information system prevent the establishment of accounting information system in companies' financial units. For the above hypothesis single- sample Ttest using SPSS software with confidence level of 0.95 used and the results are mentioned in Table (7). 
Table 7: Results of testing sixth hypothesis

\begin{tabular}{llll}
\hline \multicolumn{3}{c}{ Test Value $=12$} \\
\hline sixth hypothesis & degree of freedom & T & Significant level \\
Environmental factors & 96 & $102 \cdot 105$ & 0.001
\end{tabular}

HO: $\mathrm{M}=12$ )

(H1: = M> 12

Information contained in the table (7) shows 0.001 level of significant, and since the significance level less than 0.005 , is accepted, $\mathrm{HO}$ rejected, so $\mathrm{H} 6$ is approved. Hence, we can say that environmental factors can also regard as barriers in establishment of accounting information system in companies located in stock exchange.

\section{Conclusion and Discussion:}

Middle managers prevent implementation of AIS in companies listed on TSE. Results of above hypothesis through single-sample T-test with confidence level of 0.95 represent the acceptance of this hypothesis of the research. It means that middle managers are of affecting barriers in failure of implementation of accounting information system in companies located stock exchange .There is a meaningful relation between middle managers and implementation of accounting information system. Further, environmental factors prevent the implementation of AIS listed companies on TSE. Results of the above hypothesis through single-sample T-test with confidence level of 0.95 represent the acceptance of this hypothesis in the research. It means that organizational structure is one of affecting barriers in failure of implementing AIS in companies listed on TSE. There is a meaningful relation between and between organizational structure and implementation of AIS. By the way the results reveal that organizational culture prevents the implementation of AIS listed companies on TSE. Results of the above hypothesis through single-sample T-test with confidence level of 0.95 represent the acceptance of this hypothesis in the research. It means that organizational culture is one of the affecting barriers in failure of implementing accounting information system in companies located in stock exchange. It means that there is meaningful relation between organizational culture and implementation of accounting information. The authors come to conclusion that several barriers lead to implementation AIS on listed companies on TSE. In such a condition it seems that without solving these problems the Iranian companies do not enjoy of advantages of AIS, so it cause very big problem in near future. In order to solving these problems all together from top managers to simple clerk should give hand in hand and at least reduce these problems in competition world.

\section{References}

Ahmad, A., Mehra, S. and Pletcher, M. (2004): The perceived impact of JIT implementation on firms' financial/growth performance, Journal of Manufacturing Technology Management, 15(2):118 - 130.

Alles, G. M., Kogan, A \& Vasarhelyi, A. M, (2008): exploiting comparative advantage: A paradigm for value added research in accounting information systems, international journal of accounting information systems, 9: 202-215.

Allott, A. (2000): Some Academics Say Management Accounting Has Not Changed in The Last 60 Years; Others Say It Has-Hugely Who's Right, Asks Anita Allott?, Management Accounting: Magazine for Chartered Management Accountants, 78 (7):54-56

Bagaeva, A. (2008): An examination of the effect of international investors on accounting information quality in Russia, advances in accounting, 24: 157-161

Bergeron F., Raymond L., \& Rivard S. (2001): Fit in strategic information technology management research: an empirical comparison of perspectives. OMEGA, International Journal of Management Science; 29:42125.

Bharadwaj A. S. (2000): A resource-based perspective on information technology capability and firm performance: an empirical investigation, MIS Quarterly; 24(1):169-96

Boulianne, E. (2007): Revisiting fit between AIS design and performance with the analyzer strategic-type, international journal of accounting information systems: 1-16 
Bowen, P. L., Cheung, Y. M and Rohde, F. H. (2007): Enhancing IT governance practices: A model and case study of organizations efforts, international journal of accounting information systems, 8: 191-221

Bradley, J. (2008): Management based critical success factors in the implementation of enterprise resource planning systems, international journal of accounting information systems, 9:175-200

Bruque, S. and Moyano, J. (2007): Organizational determinants of information technology adoption and implementation in SMEs: the case of family and cooperative firms, technovation, 27:241-253

Callen J. L., Morel, M. and Fader, C. (2005): Productivity Measurement and the Relationship between Plant Performance and JIT Intensity, Contemporary Accounting Research, 22(2): 271-309

Cheatham, C. B. and Cheatham, L. R. (1996): Redesigning Cost Systems: Is Standard Costing Obsolete?, Accounting Horizons, 10( 4):117-125.

Curtis, M. B. \& Payan, A. (2008): An examination of contextual factors and individual characteristics affecting technology implementation decisions in auditing, international journal of accounting information systems, 9:104-121.

Drury, C. (1990): Cost Control and Performance Measurement In an Amt Environment., Management Accounting:40-44.

Edenburg, L., Soderstrom, N. Willis, V. \&, Wu, A, (2009): Behavioral changes following the collaborative development of an accounting information system, accounting organizations and society, in press, corrected proof, available online.

Elbashir, M. Z., collier, P. A. \& Davern, M. J. (2008): Measuring the effects of business intelligence systems: the relationship between business process and organizational performance, international journal of accounting information systems: $135-153$.

Ezzamel, M. (1992): Business Unit \& Divisional Performance Measurement, CIMA, Academic Press, London.

Falconer, M. C., Reid, G. \& Terry, N., (1997): Venture capital supply and accounting information system development, 1-27.

Frederick, H. W. (1984): Accounting information systems and practice, New York, Macgraw-Hill.

Fullerton, R. R. and McWatters, C. S. (2001): The production performance benefits from JIT implementation, Journal of Operations Management, 19(1): 81 - 96

Fullerton, R. R. and McWatters, C. S. (2001): The production performance benefits from JIT implementation. Journal of Operations Management, 19(1): 81 - 96.

Gil, N. (2009): Management information system and strategic performances: the role of top team composition, international journal of information management, 29,104-110.

Giunipero, L., Pillai, K., Chapman, S. \& Clark, R. (2005): A longitudinal examination of JIT purchasing practices. The International Journal of Logistics Management, 16(1): 51-70

Hall, M. (2009): Accounting information and managerial work, accounting organizations and society, in press, corrected proof,

Hall, R. W. (1983): Zero Inventory Crusade - Much More Than Material Management, Production and Inventory Control Society, 24(3): 1-9.

Hendricks, J. A. (1994): Performance Measures For a JIT Manufacturer: The Role of the IE." Industrial Engineering, 24-32.

Huber G. P. (1990): A theory of the effects of advanced information technologies on organizational design, intelligence, and decision-making. Academic Management Review, 15: 47-71.

Huber G. P. and Power D. J. (1985), Retrospective reports of strategic-level managers: guidelines for increasing their accuracy, Strategic Manage J; 6 (2), pp.171-80.

Inman, R. A. and Mehra, S. (1993): Financial justification of JIT implementation, International Journal of Operations \& Production Management, 13(4):32 - 39

Kren, L. (1992): Budgetary participation and managerial performance: The impact of information and environmental volatility. Account Review; 67: 511-26

Lautier, W. (2001): Accounting theory \&practice, seventh edition England, Foundational times Prentices Hall.

Mauldin E. G. and Ruchala, L. V. (1999): Towards a meta-theory of accounting information systems. Accounting, Organization and Society; 24, 31-317.

McMahon R. G. P. and Davies L. G. (1994): Financial reporting and analysis practices in small enterprises: Their association with growth rate and financial performance. Journal of Small Business Management; 11: 92-475.

Mcnair, C. J., Lynch R. L. and Cross, K. F. (1990): Do Financial and Non-financial Performance Measures Have to Agree? Management Accounting, November: 29.

Mia, L. and Chenhall, R. H. (1994): The usefulness of management accounting systems, functional differentiation and managerial effectiveness. Accounting, Origination and Society; 19:1-13

Mistry, J. J. (2005): Origins of profitability through JIT processes in the supply chain. Industrial Management and Data Systems, 105(6):752 - 768. 
Mitchell, F. Reid, G., and Smith J. (2000): Information system development in the small firm: the use of management accounting CIMA Publishing.

Mohdshaari, A. (2008): Utilization of data mining technology within the accounting information system in the public sector: a country study-Malaysia.

Noor A. E. \& King, M. (2005), firm performance and AIS alignment in Malaysian SME s, international journal of accounting information systems, 6: 241-259.

Rom, A. \& Rohde, C. (2007): Management accounting and integrated information systems a literature review, international journal of accounting information systems, 8:40-60.

Romeney, B., and Steinbart, J. (2003): Accounting information systems $9^{\text {th }}$ edition, prentice hall business publishing.

Salehi M., Alipour M. and Ramazani, M. (2010 b): Impact of IT on Firms' Financial Performance: Some Iranian Evidence, Global Journal of Management and Business Research, 10(4), 21-29.

Salehi M. and Alipour, M. (2010): E-banking in Emerging Economy: Empirical Evidence of Iran, International Journal of Economic and Finance, 2(1): 201-209

Salehi M., Moradi, M. and Ariyanpour, A. (2010 a): A Study of the Integrity of Internet Financial Reporting: Empirical Evidence of Emerging Economy, Global Journal of Management and Business Research, 10(1), 148-158

Sutton, G. (2000): The changing face of accounting in an information technology dominated world, international journal of accounting information systems,1-8.

Swamidass, P. M. (2007): The effect of TPS on US manufacturing during 1981 - 1998: Inventory increased or decreased as a function of plant performance, International Journal of Production Research, 45(16): 3763 - 3778.

Teubner, A. (2007): Strategic information systems planning: a case study from the Financial services industry, the journal of strategic information systems, 16:105-125.

Vasarhelyi, M. \& Alles, G. (2008): The "now" economy and the traditional accounting reporting model: opportunities and challenges for AIS research, international journal of accounting information systems, 9:227-239.

White, R., Pearson, J. \& Wilson, J. (1999): JIT Manufacturing: A Survey of Implementations in Small and Large U.S. Manufacturers, Management Science, 45(1): 1-15.

$\mathrm{Xu}, \mathrm{H} .$, (2005): Critical success factors for accounting information systems data quality, advances in management information systems, 1:197.

Zimmerman J. L. (1995): Accounting for decision-making and control, Chicago: Irwin. 